\title{
PROCALCITONINA COMO MÉTODO ALTERNATIVO À CISTOGRAFIA CONVENCIONAL NO DIAGNÓSTICO INICIAL, SEGUIMENTO E CONTROLE DO TRATAMENTO DE CRIANÇAS COM REFLUXO VESICOURETERAL: REVISÃO SISTEMÁTICA E METANÁLISE.
}

\author{
ALBERTO CEZAR SANTOS ALMEIDA FILHO'; ${ }^{1}$ Márcia Carvalho Bessa² \\ 1. Bolsista FAPESB, Graduando em Medicina, Universidade Estadual de Feira de Santana, e-mail: beto.cezar@hotmail.com \\ 2. Orientador, Departamento de Saúde, Universidade Estadual de Feira de Santana, e-mail: mcarvalhobessa@gmail.com
}

PALAVRAS-CHAVE: Procalcitonina; Refluxo Vesicoureteral; Metanálise.

\section{INTRODUÇÃO}

A infecção do trato urinário (ITU) é a infecção bacteriana mais comum na população pediátrica (SUN et al., 2013). Não existe protocolo consensual, ideal e aplicável na investigação de todas as crianças com ITU febril. Os protocolos mais aceitos são centrados na uretrocistografia, técnica reprodutível e disponível, mas com inconvenientes significativos. Biomarcadores séricos e urinários podem ser úteis na predição de suscetibilidade a cicatrizes renais e na identificação do refluxo vesicoureteral (RVU).

Alguns estudos sugerem a procalcitonina como preditora de RVU (SUN et al., 2013). A despeito dos resultados promissores, os estudos com esse biomarcador ainda são iniciais e com aplicação clinica ainda não definida em crianças com ITU (LIAO et al., 2014).

\section{MATERIAL E MÉTODOS OU METODOLOGIA}

O presente trabalho teve como objetivo realizar uma revisão sistemática de literatura e metanálise dos estudos sobre a acurácia diagnóstica do marcador inflamatório procalcitonina como método inicial e alternativo à cistografia convencional no diagnóstico dos refluxos de alto grau em crianças com ITU febril.

Foram utilizadas as bases de dados Pubmed, Web of Science, EMBASE e Google Scholar. A seleção dos artigos seguiu a estratégia baseada nos critérios da "Preferred Reportig Items for Systematic Reviews and Meta-analyses". A pesquisa dos artigos utilizou os descritores: "procalcitonin", "cystoureterography", e "vesicoureteral reflux" dos artigos publicados em inglês nos últimos 25 anos. Na metanálise empregou-se o programa estatístico Meta-Disc®.

\section{RESULTADOS E DISCUSSÃO}

Para a presente metanálise, considerou-se estudos que correlacionassem o nível séricos de procalcitonina o refluxo vesicoureteral diagnosticado à cintilografia convencional com em crianças com infecção do trato urinário (ITU).

A pesquisa dos artigos publicados incluindo os três descritores: "procalcitonin", "cystoureterography", e "vesicoureteral reflux", teve como resultado 8 artigos relevantes. Após leitura dos resumos, 3 artigos foram excluídos por não se adequarem ao objetivo proposto. Outro artigo foi excluído por usar cutoff diferente do proposto para análise. Assim, 4 artigos foram incluídos para análise, representando 668 crianças 
( $\mathrm{n}=668)$. Esses estudos foram publicados entre 2005 e 2014 e, dentre esses, 3 artigos foram estudos prospectivos e 1 estudo foi retrospectivo.

Utilizou-se como cutoff o nível sérico de procalcitonina $\geq 0,5 \mathrm{ng} / \mathrm{mL}$, por ser o valor que mais se repetiu nos artigos selecionados, considerando-se como "positivo" os valores maiores ou iguais a esse valor e "negativo" os valores inferiores. Em relação ao RVU, considerou-se como "positivo" a presença de RVU de qualquer grau diagnosticado à cistoureterografia. A análise dos dados demonstrou uma prevalência de refluxo vesicoureteral (RVU) de qualquer grau de 26,1\%. A análise estatística dos parâmetros diagnósticos está presente na tabela 1.

TABELA 1 - PARÂMETROS DIAGNÓSTICOS:

PROCALCITONINA $\geq 0,5 \mathrm{ng} / \mathrm{mL}$ versus RVU DE QUALQUER GRAU(IC 95\%)

SENSIBILIDADE

ESPECIFICIDADE

ÍNDICE DE PROBABILIDADE POSITIVA

ÍNDICE DE PROBABILIDADE NEGATIVA

ODDS RATIO DIAGNÓSTICA

ACURÁCIA

VALOR PREDITIVO POSITIVO (VPP)

VALOR PREDITIVO NEGATIVO (VPN)
$77,8 \%(71 \%-83,6 \%)$

$44,5 \%(40 \%-49 \%)$

$1,42(1,15-1,75)$

$0,521(0,389-0,697)$

$2,768(2,073-3,695)$

$53,44 \%$

$34 \%$

$84,4 \%$

\section{CONCLUSÃO}

O nível sérico de procalcitonina $\geq 0,5 \mathrm{ng} / \mathrm{mL}$ apresentou moderada acurácia para predizer RVU de alto grau em crianças com ITU, com alta sensibilidade e baixa especificidade. Além da especificidade, apresentou também um baixo valor preditivo positivo. Por outro lado, o valor preditivo negativo foi alto.

A análise conjunta desses resultados nos permite concluir que valores séricos de procalcitonina inferiores a $0,5 \mathrm{ng} / \mathrm{mL}$ possam excluir a presença do RVU de qualquer grau, mas quando positiva, a uretrocistografia é necessária para diagnóstico.

Assim, crianças com ITU e procalcitonina negativa podem não precisar da uretrocistografia na avaliação inicial, o que evita os inconvenientes relacionados ao procedimento, e possivelmente, diminui os custos iniciais da avaliação. 


\section{REFERÊNCIAS}

HALIMI-ASL, A; HOSSEINI, A. H; NABAVIZADEH, P; Can Procalcitonin Reduce Unnecessary Voiding Cystoureterography in Children with First Febrile Urinary Tract Infection? Iran J Pediatr. Aug 2014; Vol 24 (4), Pp: 418-422.

IPEK, I. O. et al; Relationship Between Procalcitonin Levels and Presence of Vesicoureteral Reflux During First Febrile Urinary Tract Infection in Children. Pediatric Urology. Nov. 15, 2011.

LEROY, S; Procalcitonin as a Predictor of Vesicoureteral Reflux in Children With a First Febrile Urinary Tract Infection. PEDIATRICS. Vol. 115 (6) Jun. 2005.

LEROY, S; Procalcitonin to Reduce the Number of Unnecessary Cystographies in Children with a Urinary Tract Infection: A European Validation Study. J PEDIATR; 150:89-95. 2007.

LIAO, P. et al. Comparison of procalcitonin and different guidelines for first febrile urinary tract infection in children by imaging. Pediatr Nephrol.. v.. 29, n. 9, p. 156774. Set. 2014. 